\title{
Acute respiratory alkalosis occurring after endoscopic third ventriculostomy
} -A case report-

\author{
Hui-Jin Sung ${ }^{2}$, Ju-Tae Sohn ${ }^{1,2}$, Jae-Gak Kim², Il-Woo Shin ${ }^{2}$, Seong-Ho Ok ${ }^{2}$, Heon-Keun Lee ${ }^{2}$, and \\ Young-Kyun Chung ${ }^{2}$ \\ ${ }^{1}$ Institutes of Health Sciences, ${ }^{2}$ Department of Anesthesiology and Pain Medicine, Gyeongsang National University School of \\ Medicine, Jinju, Korea
}

An endoscopic third ventriculostomy was performed in a 55-year-old man with an obstructive hydrocephalus due to aqueductal stenosis. The vital signs and laboratory studies upon admission were within the normal limits. Anesthesia was maintained with nitrous oxide in oxygen and $6 \%$ desflurane. The patient received irrigation with approximately 3,000 $\mathrm{ml}$ normal saline during the procedure. Anesthesia and operation were uneventful. However, he developed postoperative hyperventilation in the recovery room, and arterial blood gas analysis revealed acute respiratory alkalosis. We report a rare respiratory alkalosis that occurred after an endoscopic third ventriculostomy. (Korean J Anesthesiol 2010; 59: S194-S196)

Key Words: Acute respiratory alkalosis, Endoscopic third ventriculostomy.

A third ventriculostomy is common endoscopic procedure, and refers to fenestration of the floor of the third ventricle to create communication between the third ventricle and basilar cisterna [1]. This technique is applied mostly to patients with an obstructive hydrocephalus $[1,2]$. This form of hydrocephalus results from impaired cerebrospinal fluid (CSF) flow through the Sylvian aqueduct or fourth ventricle outlets. The complications associated with an endoscopic third ventriculostomy include minor or major intraventricular hemorrhage, pneumocephalus, injury to the paraventricular structure (basal ganglia, hypothalamus, brain stem) and cardiopulmonary depression (arrhythmia) [1]. We report a rare respiratory alkalosis [3] which was successfully treated with controlled mechanical ventilation after an endoscopic third ventriculostomy.

\section{Case Report}

A 55-year-old man was admitted to the general ward at a Gyeongsang National University Hospital with an obstructive hydrocephalus visualized by brain magnetic resonance imaging. A ventriculoperitoneal shunt had been placed 2 years earlier due to an obstructive hydrocephalus, but the physical examination was within the normal limits with the exception of an upward gaze disturbance. His vital signs were stable.

Received: December 18, 2009. Revised: 1st, January 20, 2010; 2nd, May 3, 2010. Accepted: May 26, 2010.

Corresponding author: Ju-Tae Sohn, M.D., Department of Anesthesiology and Pain Medicine, Gyeongsang National University School of Medicine, 92, Chiram-dong, Jinju 660-702, Korea. Tel: 82-55-750-8586, Fax: 82-55-750-8142, E-mail: jtsohn@nongae.gsnu.ac.kr (c) This is an open-access article distributed under the terms of the Creative Commons Attribution Non-Commercial License (http:// creativecommons.org/licenses/by-nc/3.0/), which permits unrestricted non-commercial use, distribution, and reproduction in any medium, provided the original work is properly cited. 
The laboratory studies including a complete blood count, electrocardiogram, liver and renal function tests were within the normal limits. A chest posteroanterior radiography revealed ventriculoperitoneal shunt in place.

The patient was premedicated with midazolam $(2.5 \mathrm{mg})$ and glycopyrrolate $(0.2 \mathrm{mg})$. Anesthesia was induced with $250 \mathrm{mg}$ sodium thiopental and $50 \mathrm{mg}$ rocuronium while he received oxygen $(5 \mathrm{~L} / \mathrm{min})$ through a face mask. Fiberoptic orotracheal intubation was then accomplished using a reinforced endotracheal tube (internal diameter: $7.5 \mathrm{~mm}$ ). Anesthesia was maintained with nitrous oxide in oxygen (50\%: $50 \%)$ and 6 vol\% desflurane. The intraoperative end-tidal carbon dioxide tension was maintained within $30-35 \mathrm{mmHg}$. He received irrigation with approximately 3,000 $\mathrm{ml}$ normal saline at room temperature while introducing the neuroendoscope (MINOP neuroendoscopy system, Aesculap, Center Valley, Pennsylvania, USA) with a shaft diameter of $2.7 \mathrm{~mm}$, a maximum infusion rate of $1,000 \mathrm{ml} / \mathrm{min}$ and a maximum pumping pressure of $500 \mathrm{mmHg}$. During the surgical procedure, irrigation fluid was naturally drained and the neuroendoscopic intracranial pressure was not measured because monitoring equipment was unavailable. Two hours after beginning the procedure, his systolic blood pressure and heart rate increased from 100 $\mathrm{mmHg}$ to $170 \mathrm{mmHg}$ and from $45-90$ beats $/ \mathrm{min}$ to $100-110$ beats/min, respectively. Intravenous hydralazine $(10 \mathrm{mg})$ and esmolol (10 mg) was administered to control the increased blood pressure and heart rate. However, the increased heart rate persisted from 2 hours after beginning the procedure to the end of the operation. Otherwise, the operation and anesthesia were uneventful.

In order to rule out a postoperative hemorrhage, brain computerized tomogram taken immediately after the endoscopic third ventriculostomy revealed the external ventricular drainage catheter and pneumocephalus on the left frontal convexity. The neuromuscular blockade was reversed with $15 \mathrm{mg}$ pyridostigmine and $0.4 \mathrm{mg}$ glycopyrrolate. Although he showed mild confusion, the patient was extubated after confirming adequate voluntary respiration. The patient remained in the recovery room because he showed mild con-

Table 1. Arterial Blood Gas Analysis

\begin{tabular}{lcccc}
\hline & $\mathrm{pH}$ & $\begin{array}{c}\mathrm{PaCO}_{2} \\
(\mathrm{mmHg})\end{array}$ & $\begin{array}{c}\mathrm{PaO}_{2} \\
(\mathrm{mmHg})\end{array}$ & $\begin{array}{c}\mathrm{HCO}_{3} \\
(\mathrm{mmol} / \mathrm{L})\end{array}$ \\
\hline Preoperation & 7.47 & 30 & 77 & 21 \\
Preextubation & 7.29 & 36 & 102 & 17.3 \\
4 hours after extubation & 7.58 & 21 & 70 & 19.7 \\
Mechanical ventilation & 7.51 & 28 & 123 & 25 \\
After extubation & 7.40 & 39 & 121 & 24 \\
10 hours after extubation & 7.44 & 35 & 78 & 23 \\
\hline
\end{tabular}

$\mathrm{PaCO}_{2}$ : arterial carbon dioxide tension, $\mathrm{PaO}_{2}$ : arterial oxygen tension. fusion after extubation. Four hours after surgery, the respiratory rate increased to $50-66 / \mathrm{min}$ and he showed seizure-like movements. Although administering intravenous diazepam (10 $\mathrm{mg}$ ), haloperidol (3 mg) and orfil (300 $\mathrm{mg}$ ) to treat the seizurelike movement, mild seizure-like activity such as myoclonal jerk persisted for 2 hours and was treated successfully with intravenous administration of another $10 \mathrm{mg}$ diazepam used for endotracheal intubation. Arterial blood gas analysis at that time revealed acute respiratory alkalosis (Table 1). The patient was transferred to the intensive care unit. Orotracheal intubation using a direct laryngoscope was then performed with the intravenous administration of $10 \mathrm{mg}$ diazepam, and controlled mechanical ventilation (assist-control mechanical ventilation mode: tidal volume; $500 \mathrm{ml}$, respiratory rate; 16/min, inspired oxygen fraction; $40 \%$ ) was applied for 15 hours (Table 1). The hyperventilation was treated successfully with controlled mechanical ventilation. Ventilator weaning was accomplished on the first postoperative day (Table 1). He was transferred to the general ward on the second postoperative day.

\section{Discussion}

The complication rate for endoscopic third ventriculostomy ranges from $6 \%$ to $8 \%$, and is similar to the expected infection rate of a shunt [4]. The complications of an endoscopic third ventriculostomy include cerebrospinal fluid leak, pneumocephalus, ventriculitis, subdural hematoma, injury to the periventricular structures (hypothalamus, basal ganglia and brain stem), bradycardia, asystole, minor bleeding and hypokalemia $[2,4]$.

The etiology of respiratory alkalosis includes hypoxia, parenchymal lung disease, bronchial asthma, drug, mechanical ventilation, central nervous system disorder, metabolic causes and hyperventilation [5]. Respiratory alkalosis associated with hyperventilation was detected in our patient 4 hours after extubation. The floor of the third ventricle is not a membrane but a part of the hypothalamus [4]. Massive or high-speed irrigation with normal saline has been associated with a hypothalamic dysfunction. As the neuroendoscope used in this patient was not equipped with device for a critical setting of infusion rate and pumping pressure, an unchecked maximum infusion rate $(1,000 \mathrm{ml} / \mathrm{min})$ and pumping pressure $(500$ $\mathrm{mmHg}$ ) which produce a transient increase in pressure inside neuroendoscope may cause a transient injury of periventricular structures such as hypothalamus. Late arousal and postoperative confusion are caused by trauma to the sensitive hypothalamic structures [4]. A $>30 \mathrm{mmHg}$ pressure inside the endoscope is associated with postoperative morbidity, particularly unexpected delayed recovery [6]. Hypothalamicmesencephalic dysfunction is associated with hypertension, 
hyperthermia, and hyperventilation [7]. It is very difficult to determine the causes of hyperventilation observed in this patient. The possible causes are as follows. First, considering the above reports $[6,7]$, hypothalamic dysfunction caused by an unrecognized increased intracranial pressure due to the high-speed irrigation of normal saline during an endoscopic third ventriculostomy may contribute to the hyperventilation observed in the recovery room. A critical setting of infusion rate and pumping pressure during an endoscopic third ventriculostomy might help reduce pressure transferring to periventricular structures. Therefore, we recommend that the neuroendoscopic intracranial pressure be monitored to prevent the complications associated with hypothalamic dysfunctions. Second, this hyperventilation may be partially associated with CSF acidosis induced by normal saline irrigation used during the procedure. The $\mathrm{pH}$ of the cerebrospinal fluid is 7.31 , whereas that of normal saline is 6.1 [8]. A total of $3,000 \mathrm{ml}$ normal saline used during the endoscopic third ventriculostomy would fill the enlarged lateral and third ventricles with normal saline instead of CSF. After fenestrating the floor of the third ventricle, acidic normal saline in the enlarged lateral and third ventricles drained into the interpuduncular cisterna filled with CSF, which might have led to a more acidic CSF compared to normal CSF. An acidosis of the CSF produces hyperventilation by stimulating the central chemoreceptor. Central lactate production of a meningeal tumor can also cause CSF acidosis, which induces hyperventilation and respiratory alkalosis [9]. The capacity of the male elderly lateral and third ventricle is $35.19 \pm 20.35$ and $2.63 \pm 0.96 \mathrm{ml}$, respectively [10]. Our findings and those of previous reports [8-10] suggest that the $\mathrm{pH}$ in the CSF and arterial blood should be measured simultaneously to confirm the respiratory alkalosis caused by normal saline irrigationinduced CSF acidosis.

The causes of peripheral hyperventilation [5], which include hypoxia, parenchymal lung disease, medication, mechanical ventilation, central nervous system disorder and metabolic disturbance, were excluded by a physical examination and laboratory tests.

In conclusion, central neurogenic hyperventilation was developed in a patient receiving high-speed irrigation and large amount of normal saline (maximum infusion rate of $1000 \mathrm{ml}$ / min and maximum pumping pressure of $500 \mathrm{mmHg}$ ) during an endoscopic third ventriculostomy, which may be ascribed to a transient hypothalamic dysfunction and/or acidic CSF. This type of hyperventilation was treated successfully by controlled mechanical ventilation.

\section{References}

1. Huhn SL, Feaster WW, Larson CP. Pediatric surgery. In: Anesthesiologist's Manual of Surgical Procedures. 3rd ed. Edited by Jaffe RA, Samuels SI: Philadelphia, Lippincott Williams \& Willikins. 2004, pp 945-8.

2. El-Dawlatly A, Elgamal E, Murshid W, Alwatidy S, Jamjoom Z, Alshaer A. Anesthesia for third ventriculostomy. A report of 128 cases. Middle East J Anesthesiol 2008; 19: 847-57.

3. Souto-Ferro JM, Valero-Castell R, Fábregas-Julià N, CarreroCardenal E. Postoperative respiratory alkalosis as a complication of neuroendoscopy. Rev Esp Anestesiol Reanim 1997; 44: 83-5.

4. Walker ML. Complications of third ventriculostomy. Neurosurg Clin N Am 2004; 15: 61-6.

5. Foster GT, Vaziri ND, Sassoon CS. Respiratory alkalosis. Respir Care 2001; 46: 384-91.

6. Fabregas N, López A, Valero R, Carrero E, Caral L, Ferrer E. Anesthetic management of surgical neuroendoscopies: usefulness of monitor pressure inside the neuroendoscope. J Neurosurg Anesthesiol 2000; 12: 21-8.

7. Pranzatelli MR, Pavlakis SG, Gould RJ, De Vivo DC. Hypothalamicmidbrain dysregulation syndrome: hypertension, hyperthermia, hyperventilation, and decerebration. J Child Neurol 1991; 6: 115-22.

8. Artru AA. Cerebrospinal fluid. In: Anesthesia and Neurosurgery. 4th ed. Edited by Cottrell JE, Smith DS: Phildelphia, Mosby. 2001, pp 84-5.

9. Blüher S, Schulz M, Bierbach U, Meixensberger J, Trobs RB, Hirsch W, et al. Central lactic acidosis, hyperventilation, and respiratory alkalosis; leading clinical features in a 3 -year-old boy with malignant meningeal melanoma. Eur J Pediatr 2008; 167: 483-5.

10. Coffey CE, Lucke JF, Saxton JA, Ratcliff G, Unitas LJ, Billig B, et al. Sex differences in brain aging: a quantitative magnetic resonance imaging study. Arch Neurol 1998; 55: 169-79. 